Infrastructure Asset Management

Volume 2 Issue 3

The impacts of climate change on UK energy demand

Wood, Calverley, Glynn et al.
Infrastructure Asset Management, 2015, 2(3), 107-119

http://dx.doi.org/10.1680/iasma.14.00039

Paper 1400039

Received 22/11/2014; accepted 20/07/2015

Keywords: weather/energy/sustainability

\title{
The impacts of climate change on UK energy demand
}

\section{Frances Ruth Wood PhD}

Lecturer, Tyndall Centre for Climate Change Research, University of

Manchester, Manchester, UK; School of Mechanical, Aerospace and Civil

Engineering, University of Manchester, Manchester, UK

\section{Daniel Calverley PhD}

Research Associate, Tyndall Centre for Climate Change Research, University of Manchester, Manchester, UK; School of Mechanical, Aerospace and Civil Engineering, University of Manchester, Manchester, UK

\section{Steven Glynn PhD}

Research Associate, Tyndall Centre for Climate Change Research, University of Manchester, Manchester, UK; School of Mechanical, Aerospace and Civil Engineering, University of Manchester, Manchester, UK

\section{Sarah Mander PhD}

Research Fellow, Tyndall Centre for Climate Change Research, University of Manchester, Manchester, UK: School of Mechanical, Aerospace and Civil

Engineering, University of Manchester, Manchester, UK

\section{Conor Walsh PhD}

Research Associate, Tyndall Centre for Climate Change Research, University of Manchester, Manchester, UK; School of Mechanical, Aerospace and Civil Engineering, University of Manchester, Manchester, UK

Jaise Kuriakose MSc

Doctoral Researcher, Tyndall Centre for Climate Change Research, University of Manchester, Manchester, UK; School of Mechanical, Aerospace and Civil Engineering, University of Manchester, Manchester, UK

Frances Hill MSC

Doctoral Researcher, School of Mechanical, Aerospace and Civil

Engineering, University of Manchester, Manchester, UK

Mirjam Roeder PhD

Research Associate, Tyndall Centre for Climate Change Research, University of Manchester, Manchester, UK; School of Mechanical, Aerospace and Civil Engineering, University of Manchester, Manchester, UK

The impacts of climate change on the energy system are diverse; this article focuses on the potential effects on UK energy demand and the ramifications for national infrastructure building on the findings of the UK's 2012 Climate Change Risk Assessment. It reviews the available literature, where it exists, on the relationships among current energy demand, weather and climate change, and the implications for these relationships due to mitigation plans and potential adaptation responses. The review highlights the mechanisms by which future climate change, in particular changes in mean and extreme temperature, could affect the annual amount of UK energy demand and the seasonal, daily and spatial variation of the impacts. Published literature quantifying the effects of climate change on UK energy demand is limited; thus, where evidence is not available, information on the current relationship between weather and demand is combined with expert judgement to highlight potential demand responses to a changing climate without quantification. The impacts identified could have significant implications for the long-term planning of energy infrastructure and system operation and building design, depending on their magnitude, highlighting the need for further research in this area.

\section{Introduction}

Long-term planning of energy infrastructure requires an appreciation of how energy demand may change over timescales of 15-30 years or more (National Grid, 2014a). Historical relationships between economic growth and energy demand will likely be significantly altered by efforts to mitigate climate change as well as its inevitable impacts and our adaptation responses; thus, demand forecasters and those involved in infrastructure planning require an understanding of these ramifications for energy demand (McColl et al., 2012; National Grid, 2014a).

Parameters of demand considered here that are likely to be affected by climate change include (but are not limited to) the following: the size of annual energy demand, the size and timing of peak demand, the spatial distribution of demand and the sector affected (Chandramowli and Felder, 2014; ENA, 2011; National Grid, 2014a, 2014b, 2014c). These parameters of demand are among those considered when planning and managing energy infrastructure. The sizes of annual energy demand and peak demand influence the amount of supply and /or storage required, for example, the available capacity of electricity supply or the amount of gas and oil stored in the UK at any given time. The timing of peak demand influences planned maintenance and construction schedules and supply planning (ENA, 2011; National Grid, 2014b, 2014c). The regional distribution of demand influences the logistics of supply, including the topology and capacity of the electricity transmission and gas distribution networks (National Grid, 2014b, 2014c). In the case of electricity, the change in demand in urban against rural areas influences the effects seen by distribution network operators due to other confounding factors such as the urban heat island effect and the differences in network configuration (networked or radial) that service these areas (ENA, 2011). Finally, the sector affected is significant as it can indicate the ability or otherwise of the sector to adapt or respond to these impacts autonomously and their overall effect on energy supply and distribution networks. Thus, identifying the impacts of climate change on 'energy demand' per se requires a systematic approach. 
In order to systematically identify the potential impacts of climate change on energy demand, this paper considers first each of the main sources of energy demand (as defined by the UK Digest of UK Energy Statistics DECC, 2014) in the UK, highlighting, where the evidence exists, the current relationships between weather and energy demand, and, how climate change may affect existing relationships. In doing this, the ramifications of weather and climate on two key dimensions of energy demand are considered, namely, $(a)$ energy service demand and $(b)$ energy service delivery. For example, heating energy demand varies with weather and is thus affected by future climate according to changes in $(a)$ user demand for heating and $(b)$ the performance of the technology that provides heating services. Changes in both dimensions are determined by interactions among infrastructure (e.g. thermal performance of buildings), technology (e.g. the heating equipment installed) and human factors (e.g. perceptions of thermal comfort), which must all be taken into consideration when assessing the implications of future climate change. Second, the paper discusses the implications for energy demand from the uptake and use of energy-dependent technologies in response to both efforts to mitigate climate change and its impacts.

The paper is structured as follows: 'Background' provides further information on the context of the paper and background information on the major observable relationships of UK energy demand with weather parameters at present and related climate impact projections. 'Impacts of climate change on energy demand' discusses key energy demand sectors, focusing on current end use patterns of the sector, their existing weather relationship and how climate impacts could influence future demand. 'Climate adaptation measures and energy demand' discusses the energy associated with some of the large-scale adaptation options, and 'Discussion and conclusions' discusses the findings in the context of wider societal changes affecting energy demand and provides the conclusion.

\section{Background}

This paper is based on a technical paper written for the Research Council UK's Living with Environmental Change (LWEC) Programme to inform their Climate Change Impact Report Card on Infrastructure (Wood et al., 2015). The series of impact report cards produced by LWEC aim to identify key risks and opportunities as a result of climate change to the UK, in this case, augmenting and updating coverage of energy demand in the UK's 2012 Climate Change Risk Assessment (McColl et al., 2012). An assessment of both risks and opportunities requires the systematic identification of all the potential impacts (as far as possible), not solely impacts that have been studied and quantified previously. Published work in this field is limited with studies tending to focus on climate impacts on heating and cooling demand (Auffhammer and Mansur, 2014; Schaeffer et al., 2012); indeed, the last UK Climate Change Risk Assessment (CCRA) 2012 identified increased cooling demand as a key risk to the energy system and reduced heating demand as an opportunity (McColl et al., 2012). However, building heating and cooling demand may not be the only form of energy demand that may be directly affected by climate change. A more detailed examination of the particular end uses of energy demand and how they, alongside the technologies and/or behaviours, interact to deliver energy services is needed to understand the potential implications on the energy system - this includes an examination of the wider factors influencing demand. The approach taken here was to consider current forms of energy demand that are weather dependent and identify how future climate and other factors could affect them (rather than take each climate impact in turn and identify how it may affect energy demand), and then consider the energy demands of potential adaptation measures to climate impacts.

The future climate is uncertain; historic greenhouse gas emissions have committed the world to a certain amount of warming already, and without significant reductions within the next decade, global mean temperature changes are likely to reach the $2^{\circ} \mathrm{C}$ limit deemed by international agreement as dangerous (IPCC, 2014). The likely impacts on the UK are diverse; here, the impacts identified by the UK Climate Impacts Programme's projections are used, with illustrative figures (Figure 1) from the medium emissions scenario, although the current global emissions trajectory is closer to the high emissions scenario (Le Quéré et al., 2014). While UKCP09 provides detailed projections, those of most relevance to the discussion below are summarised here (Murphy et al., 2010). The impacts include increases in both winter and summer mean daily minimum and maximum temperatures. The extent of these changes depends on location, with Southern England generally warming more than Scotland. Changes in other parameters are even more location specific: in England, projections suggest decreases in humidity and mean cloud cover during the summer, while in Northern Scotland, projections suggest increases in cloud cover and minimal changes in humidity during summer; changes in rainfall patterns include decreasing rainfall in parts of Southern England during summer coupled with increasing rainfall during summer in parts of Scotland (Murphy et al., 2010). Figure 1 shows the spatial distribution of some of the key climate projections in the UK; the impacts are clearly not uniform; thus, any changes in energy demand as a result of climate impacts will likely follow a similar distribution. These impacts have been used to inform the factors considered in this paper; while there are discussions of additional climate impacts such as the frequency and intensity of storm events from global climate models in the literature, probabilistic assessments for the UK of these parameters are not available (Collins et al., 2013; Murphy et al., 2010). The implications of individual extreme storm events on energy demand are considered in 'Climate adaptation measures and energy demand' section - the frequency of these events would determine the overall effect on the energy system. Considering future wind speeds, projections for the UK suggest very small changes - less than $1 \mathrm{~m} / \mathrm{s}$ increase or decrease across the UK (Sexton and Murphy, 2010).

\section{Impacts of climate change on energy demand}

This section outlines the main existing energy uses in the UK, discussing their current dependence on weather and how climate projections may alter this relationship. The section considers buildings (domestic and service sector), transport and agriculture, 


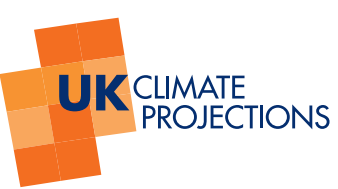

$10 \%$ probability level Very unlikely to be

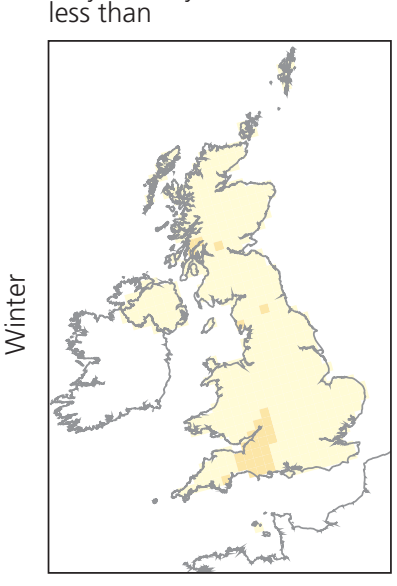

$50 \%$ probability level Central estimate
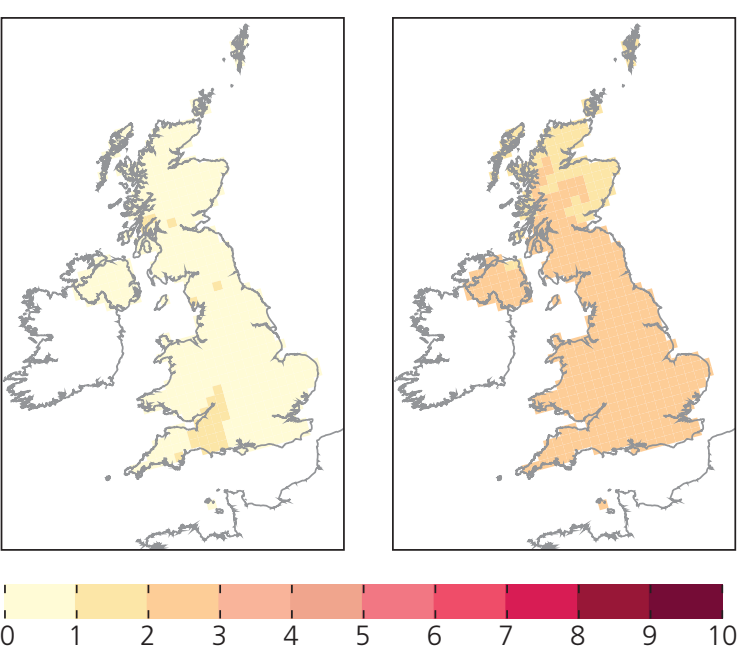

Change in winter mean minimum temperature $\left({ }^{\circ} \mathrm{C}\right)$ for the 2050 s, medium emissions scenario

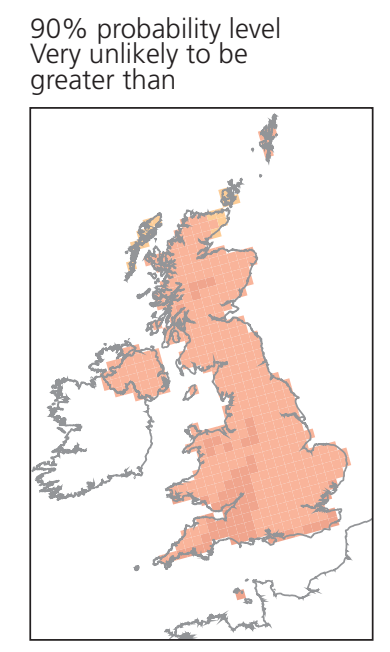

very unlikely to be greater than

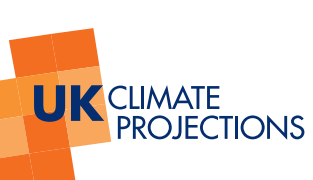

$10 \%$ probability level Very unlikely to be less than

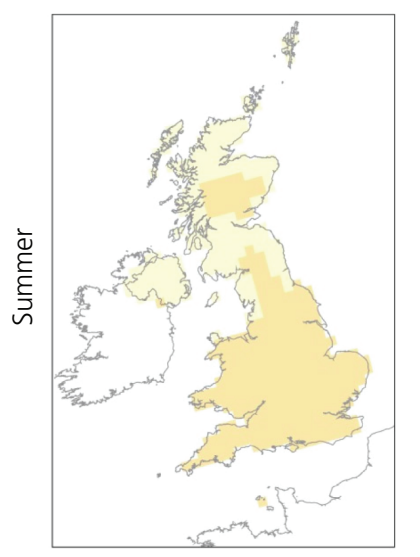

$50 \%$ probability level Central estimate

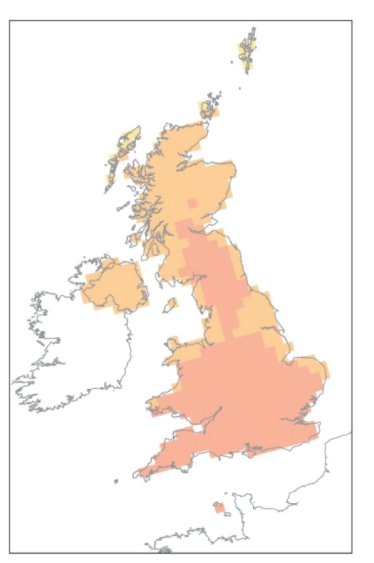
Very unlikely to be greater than
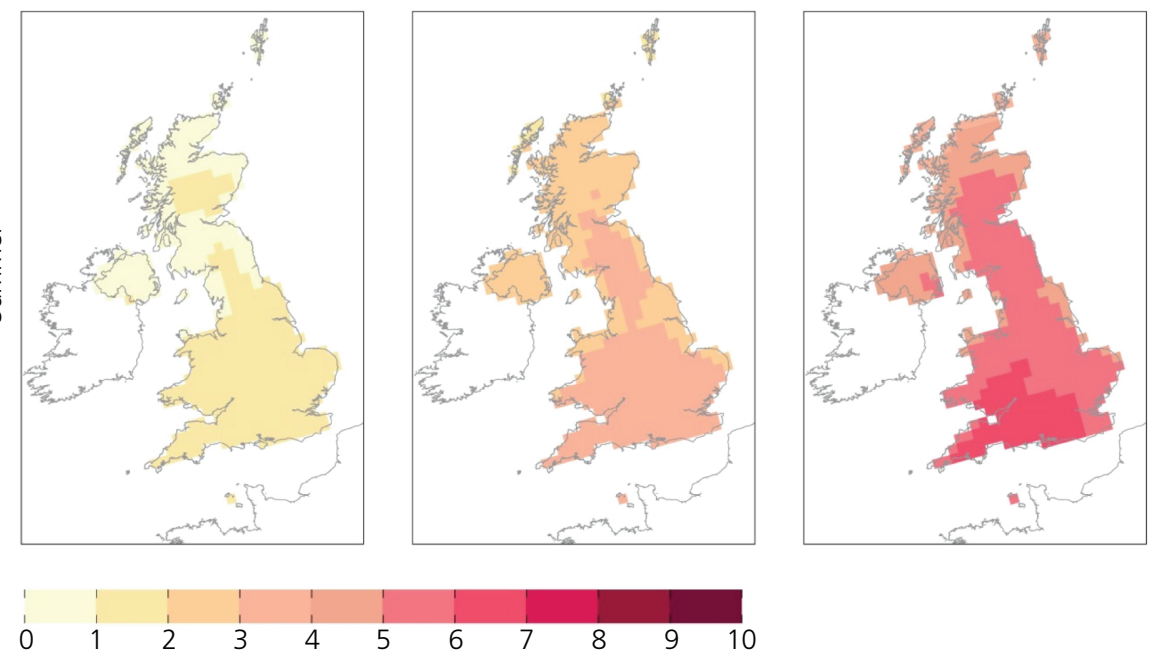

Change in summer mean maximum temperature $\left({ }^{\circ} \mathrm{C}\right)$ for the 2050 s, medium emissions scenario

Figure 1. Projections of summer maximum and winter minimum percentage temperature changes by 2050 relative to a 19611990 baseline under a medium future emissions scenario. (C) Crown Copyright 2009. The UK Climate Projections data have been made available by the Department for Environment, Food and Rural Affairs (Defra) and Department for Energy and
Climate Change (DECC) under licence from the Met Office, Newcastle University, University of East Anglia and Proudman Oceanographic Laboratory. These organisations accept no responsibility for any inaccuracies or omissions in the data, nor for any loss or damage directly or indirectly caused to any person or body by reason of, or arising out of, any use of these data 
collectively representing more than $78 \%$ of UK energy demand (DECC, 2013a; Table 1.02). The remaining sources of UK energy demand include industrial processes - these are discussed briefly in 'Energy demand from buildings and the impacts of climate change' section; however, there is very limited information about the relationship between demand and weather parameters in this sector from which to draw firm conclusions on the consequences of climate change. The paper does not attempt to quantify these changes, as the relative size of climate impacts is mediated by far wider societal, technological and economic changes that will occur over the same timeframe, with energy policy of particular significance.

Current energy policy promotes improvements in energy efficiency, energy security and reduction in the carbon intensity of energy supply (UK Government, 2015). Delivering this policy may lead to the adoption of new technologies such as heat pumps (electric or gas) and electric cars and associated changes in behaviours and practices. This changes the relative demand for each energy source, in some cases altering the relationship between end-use energy demand and weather. For example, the battery performance of electric vehicles (EVs) is related to temperature, a relationship not previously observed between the performance of cars with internal combustion engines and weather. In addition to the effects in general of population and economic growth, future energy demand will be affected by unpredictable societal trends and technological innovations; for example, the dramatic increase in the use of ICT (and the high cooling demand of IT servers) observed over the last decade was not predicted 25 years ago. Similarly, the changing relationship between energy demand and weather associated with such societal and technological changes cannot be predicted. However, new technology will emerge, and social norms and behaviours will evolve over the next decades. Therefore, when interpreting the findings of the sections below, it is important to consider them within this context.

\section{Energy demand from buildings and the impacts of climate change}

Building energy demand can be disaggregated into a number of end uses including space heating, hot water, lighting, appliances (e.g. fridges, washing machines), computing and consumer electronics, catering and space cooling. According to published studies, the main weather-dependent energy uses from the building sector at present are space heating and cooling demand, refrigeration and lighting (DECC, 2013a; Hor et al., 2005). Energy demand for the former two sources mainly relates to external temperatures and the latter to cloud cover and sunshine hours (Hor et al., 2005). Typically, heating demand increases with colder weather, and cooling demand increases in warmer weather; the elasticity of the relationships depends on the building performance and levels of thermal comfort expected by the occupants. Refrigeration demand increases in warmer temperatures; however, the effect is minimal when compared to other factors such as the frequency with which the fridge or freezer door is opened (Laguerre et al., 2002). Lighting demand typically follows daylight hours but can increase during the daytime when there is extensive cloud cover (Hor et al., 2005). Other uses of energy demand may also be influenced by factors that include weather - for example, use of tumble driers on wet days or consumption of hot drinks and thus use of kettles during colder weather. However, weather is just one in a number of factors such as availability of outdoor drying space and householder lifestyles that will affect their use, and while seasonal patterns of appliance use are observed, evidence of direct weather relationships within a season was not found (BRE, 2013).

Considering the implications of climate change on building energy demand, projections of impacts include higher mean and extreme temperatures across the UK (Murphy et al., 2010), potentially leading to reductions in energy demand for heating in the winter, but more significantly an increase in comfort cooling demand in summer months (see Figure 1 for the distribution of these changes). Predictions of cloud cover show potential increase during winter and a decrease in summer (Murphy et al., 2010), ceteris paribus increasing daytime lighting energy demand in winter and decreasing in summer; however, anticipated improvements in lighting technology will likely mitigate this effect. Other energy uses in buildings are currently less weather and therefore climate sensitive; Table 1 summarises the key interactions and their impacts on temporal and spatial energy demand profiles. Given the wide variations in thermal performance of existing building stock, occupancy profiles and expectations of thermal comfort, coupled with the various future trends affecting these factors and the spatial differences in future temperature changes, it is inappropriate to attempt to offer a precise value for absolute change in energy demand for the UK's building stock due to climate change. However, case studies of individual buildings to date enable the significant factors that influence the scale and direction of change to be identified (e.g. Chow and Levermore, 2010; Du et al., 2012; Jentsch et al., 2008; Lomas and Ji, 2009; Patidar et al., 2014; Short et al., 2012). Their findings are described in more detail below.

\section{Climate impacts on heat demand}

Space heating demand is directly related to building thermal performance, thermal comfort expectations of occupants and external temperature relative to a baseline threshold below which it is assumed heating is required, expressed as heating degree days (HDDs) (CIBSE, 2006). Projections of future HDDs and associated heating demand outlined in the Climate Change Risk Assessment (McColl et al., 2012) show an almost linear decline in HDDs out to the 2080s under each climate scenario. This change differs regionally across the UK: assuming a $15 \cdot 5^{\circ} \mathrm{C}$ threshold, by the 2080s, HDDs are forecast to fall in London by between 360 and 1214 and in the North of Scotland by between 437 and 1584, depending on the future emission scenario selected (Capon and Oakley, 2012: Appendix 5). Coupled with existing strategies to further reduce heating demand through efficiency improvements, a substantial decrease in annual heating demand could be seen by 2080s if not before if rebounds are minimised.

\section{Climate impacts on energy requirements for heating provision}

The scale of climate impacts on the efficiency of heating provision is dependent on the technology used. Current heating provision is 


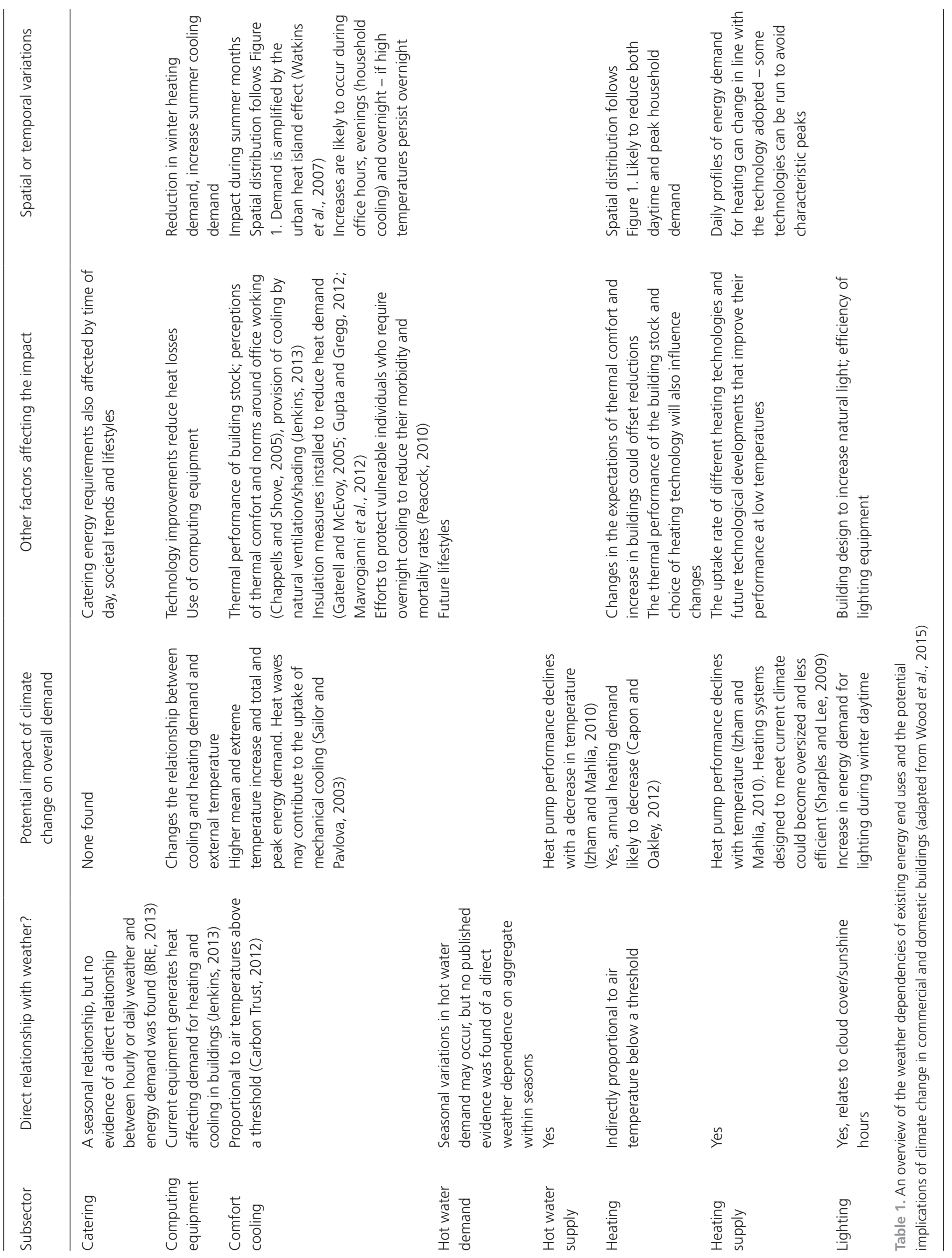


dominated by gas boilers (DECC, 2013a, 2013b); however, heat pumps (air or ground source) are currently promoted as a mitigation option. Boiler efficiency and the coefficient of performance (CoP) of heat pumps are both affected by temperature, the efficiency with which heat is produced declining during colder weather. The influence of weather on gas boiler efficiency is limited, as most appliances are sited indoors. The effect of cold weather on heat pump performance, however, can be much more significant as by design the system interacts directly with the air or the ground. For an air source heat pump, a change in temperature from $+7^{\circ} \mathrm{C}$ to $-7^{\circ} \mathrm{C}$ can see the CoP drop by $28 \%$ (Dunbabin and Wickins, 2013: p. 15). The CoP of ground source heat pumps declines with soil temperature, which is less volatile than air temperature but changes depending on the duration and severity of cold spells (Dunbabin and Wickins, 2013). Technology improvements may reduce the effect of temperature on CoP, but if more electric heat pumps are installed in line with current UK climate policy, then the overall combined effect seen by the electricity network may be greater, particularly on peak cold winter days.

\section{Climate impacts on comfort cooling demand}

Higher summer mean and extreme temperatures associated with climate change will likely result in increased demand for comfort cooling. Hotter temperatures, with a greater number of cooling degree days (CDDs), are more prevalent in southerly latitudes in climate predictions (see Figure 1 for the distribution). Projections of future CDDs outlined in the CCRA (McColl et al., 2012; Figure 5.1) provide the basis for assessing the size and spatial distribution of cooling load across the UK. Considering the average annual CDDs (based on a threshold temperature of $22^{\circ} \mathrm{C}$ ) in Southern England, the ensemble mean simulation of CDDs for 1961-1990 was approximately $25-50$; by the 2080 s, under a medium emission scenario, CDDs are forecast to increase by 125-175 (McColl et al., 2012). Smaller increases in CDDs are projected for higher latitudes, such that the increases over northern England and Scotland are 25-50 (McColl et al., 2012). In addition, growth in CDDs in urban areas is likely to be compounded by the urban heat island effect - central London, for example, can see temperatures $7^{\circ} \mathrm{C}$ warmer than rural areas only $20 \mathrm{~km}$ away (Watkins et al., 2007: p. 85).

Mechanical cooling is mainly deployed in commercial premises at present; an estimated $10 \%$ of commercial floor space was airconditioned in 1994, expected to rise to $40 \%$ by 2020 compared to just 3\% of households in 2011 (BRE, 2013; Carbon Trust, 2012). Studies assessing the impact of temperature increase on commercial cooling energy demand highlight the significance of the thermal characteristics of building materials, size of internal gains as well as passive adaptation measures in determining absolute energy demand changes (Jenkins et al., 2013; Peacock et al., 2010; Tian and de Wilde 2011). Assessing electrical cooling demand in office buildings under the UKCP09 high emissions scenario, Jenkins et al. (2013) highlight the important contribution of passive adaptation measures, such as horizontal external shading on south-facing glass and limiting heat gains from IT and lighting, to reducing future office cooling demand.
Their analysis shows consumption in adapted buildings in London rising from a current baseline of $25 \cdot 2$ to $29 \cdot 5 \mathrm{MWh} /$ year by 2080 , compared to a rise for unadapted buildings from 46 to 71.9 MWh/year. Results for Edinburgh are in similar proportion, albeit approximately one third lower in total compared to London. Tian and de Wilde's (2011) analysis indicates that for an air-conditioned university building, the level of cooling energy demand (measured in $\mathrm{kWh} / \mathrm{m}^{2}$ ) in 2050 under a low emissions scenario could be similar to heating demand, with cooling energy demand exceeding heating demand in UKCP09 medium and high scenarios. The results suggest that the yearly profile of electricity demand could change considerably with summer demand increasing from today, when summer electricity demand is much lower compared to winter.

Uptake of mechanical cooling in the domestic sector could have a major impact on the amount and diurnal load profile of UK electricity demand in summer months. Analyses from the USA highlight correlations between mechanical cooling installation and yearly CDDs coupled with economic and social factors (Sailor and Pavlova, 2003). One of the social factors that drive demand for mechanical comfort cooling is individuals' expectations concerning comfort. Expectations are shaped by many factors aside from temperature, not least exposure to air-conditioned environments outside of home; already around $70 \%$ of the car fleet and, in London, $70 \%$ of offices and $65 \%$ of retail space are air-conditioned (Peacock et al., 2010). If airconditioned space becomes people's normal experience outside their home, then similar conditions may become the expectation at home, too. Changes in domestic air conditioning (AC) use can be observed in Australia, where uptake has outpaced rising temperatures, suggesting that 'people increase their comfort expectations more rapidly than the climate is changing' (Strengers, 2008: p. 383). Similarly, in the USA, air-conditioning penetration grew from $12 \%$ to $82 \%$ of households in the 45 years from 1960 (Cox, 2010), altering the profile of peak demand by shifting it from winter evenings to summer days (Nye, 2010). In the UK, just $3 \%$ of households use fixed or portable AC units at present; however, if uptake of AC matched that of central heating, from 1970 to 2010 , the proportion of households with central heating rose from $25 \%$ to $90 \%$ (DECC, 2013b: Table 6a; BRE, 2013); uptake of AC could be very rapid indeed.

In addition to changes in mean daily temperatures, overnight temperatures are particularly significant for human health and network recovery. Peacock et al. (2010) suggest that the number of 'cooling nights' (when bedroom comfort temperature of $23.9^{\circ} \mathrm{C}$ is exceeded at 11 p.m.) in London could increase between 2005 and 2030 by up to $47 \%$, to a maximum of $105-121$ cooling nights/ year depending on the type of building. An increase in cooling nights has implications for both the health and well-being of building occupants and for the electricity network (if cooling is provided by electricity). Overnight cooling allows individuals to recover physiologically from hot weather; prolonged exposure to high temperatures is associated with excess mortality in vulnerable populations (HPA, 2012). Network cables and equipment also traditionally 'recover' overnight, cooling down when temperatures 
and demand are lower. If demand for night-time cooling leads to new overnight electricity demand, then the operational lifespan of equipment is likely to be reduced due to prolonged operation at high temperatures and load (Perez, 2012).

\section{Other impacts on future cooling demand}

At present, legal requirements to minimise cooling demand in new build are dealt with in building standards and regulations only insofar as limiting solar heat gains; it is up to developers whether they wish to go beyond the minimum required by regulation to take account of future climate change. However, with current heating demand far outstripping AC demand, the main focus of building standards has been on reducing heating demand; how this will impact on potential internal summer temperatures remains unclear. Insulation has two principal repercussions for cooling: it can impede the transmittance of solar heat through the building fabric to the rooms inside, but it can also restrict the escape of internal heat gains (e.g. from appliances) (Sharples and Lee, 2009). Some analyses show that certain measures to reduce heating demand such as curtains, insulated shutters and internal wall insulation - may actually increase summer cooling demand, whereas doubleglazing and external wall insulation may reduce overheating risk in a warming climate (Gaterell and McEvoy, 2005; Gupta and Gregg, 2012; Mavrogianni et al., 2012). Findings are mixed with respect to the impacts of loft and cavity wall insulation on future cooling demand (Gaterell and McEvoy, 2005; Gupta and Gregg, 2012; Mavrogianni et al., 2012). Changes in building techniques, such as moving to lower thermal mass construction, may also lead to an increase in summer cooling demand, although Kendrick et al. (2012) suggest that this has a much smaller effect on overheating than what has been suggested.

The impacts of warmer temperatures on energy demand will be strongly influenced by behavioural and societal responses. If rapid increases in comfort cooling demand are to be avoided, then it is important to openly debate how comfort related to hot weather should be defined (Chappells and Shove, 2005). People report feeling comfortable across a wide temperature range $\left(6^{\circ} \mathrm{C}-30^{\circ} \mathrm{C}\right)$, suggesting that there is more to comfort than temperature, with cultural factors and conventional important contributing factors (Chappells and Shove, 2005). That said, there is convergence towards the expectation that heating and cooling are provided, with a corresponding impact on energy demand, particularly as mechanical cooling becomes more common in the UK (Ackermann, 2002). Shove (2003) describes how people no longer take steps to maintain comfort, such as opening windows or wearing warmer or cooler clothes, at the same time becoming less tolerant to a wide range of temperatures. As such, the increased use of mechanical cooling is neither inevitable nor irrevocable.

\section{Cooling supply}

The $\mathrm{CoP}$ of $\mathrm{AC}$ units reduces as ambient temperature increases. Between $26^{\circ} \mathrm{C}$ and $30^{\circ} \mathrm{C}$, the $\mathrm{CoP}$ of an $\mathrm{AC}$ unit can drop by over $10 \%$ (Izham and Mahlia, 2010). The cooling efficiency of trigeneration air source heat pumps also declines at higher temperatures. CoP will be lowest when temperatures are highest and demand is greatest, compounding the effect of hotter temperatures on energy demand (Izham and Mahlia, 2010). The efficiency of new AC technology can be expected to improve in the future, but the impact of this on the relationship between temperature and energy demand is uncertain. In Australia, a move towards larger-capacity AC units has outstripped efficiency improvements, neutralising potential energy savings (Strengers, 2008). As a low-energy alternative to mechanical cooling, passive techniques such as evaporative cooling may have enhanced potential in a warmer climate, as noted by Hanby and Smith (2012) with reference to the medium UKCP09 scenario. Passive methods also have the advantage of being able to be retrofitted more readily to commercial buildings, depending on their configuration and use compared to active measures (Hanby and Smith, 2012).

\section{Heating and cooling demand and supply in other sectors}

There is minimal published information discussing the impacts of weather or climate change on energy demand for climate-controlled processes in other sectors such as food processing and chemical production. Energy demand for high- and low-temperature processes, refrigeration, space heating and drying in industrial sectors represented approximately $70 \%$ of industrial energy demand or approximately 7\% of total UK energy demand in 2012 (DECC, 2013a). It is assumed that these processes are sensitive to climate impacts; however, there is no quantification of the scale of change that climate impacts may cause.

\section{Energy demand for transportation and climate change}

The main influences of weather on transport energy demand are summarised in Table 2; they arise from ambient temperature affecting the performance of propulsion technology and demand for passenger thermal comfort (hence additional engine or battery load). Weather also influences both the amount and mode of travel demand for both passenger and agricultural freight transport; however, the size of this effect on the UK is unknown (Koetse and Rietveld, 2009). Ambient temperature also affects freight energy requirement for the refrigeration of perishable goods.

Internal combustion engines (ICEs) operate more efficiently at higher ambient air temperatures, thereby reducing energy required per kilometre (Mock et al., 2012). In test conditions, an average of $0 \cdot 161 \%$ reduction in carbon dioxide $\left(\mathrm{CO}_{2}\right)$ emitted (hence fuel consumed) was observed for each $1^{\circ} \mathrm{C}$ rise in ambient air temperature over the standard European test cycle (Kadijk et al., 2012). Increased temperatures associated with climate change are likely to yield a small reduction in energy demand from ICEs, the overall impact dependent on the extent of ICE use.

Colder air temperatures impair battery performance in EVs, effectively increasing electricity demand per kilometre of travel, depending on battery chemistry and severity of low temperature, although modern lithium ion batteries have been proven to be more resilient to cold temperatures than older lead acid and nickel-metal hydrides units, maintaining $90 \%$ of their $25^{\circ} \mathrm{C}$ discharge capacity at $-5^{\circ} \mathrm{C}$ (Horiba et al., 2005). However, climate change is not 


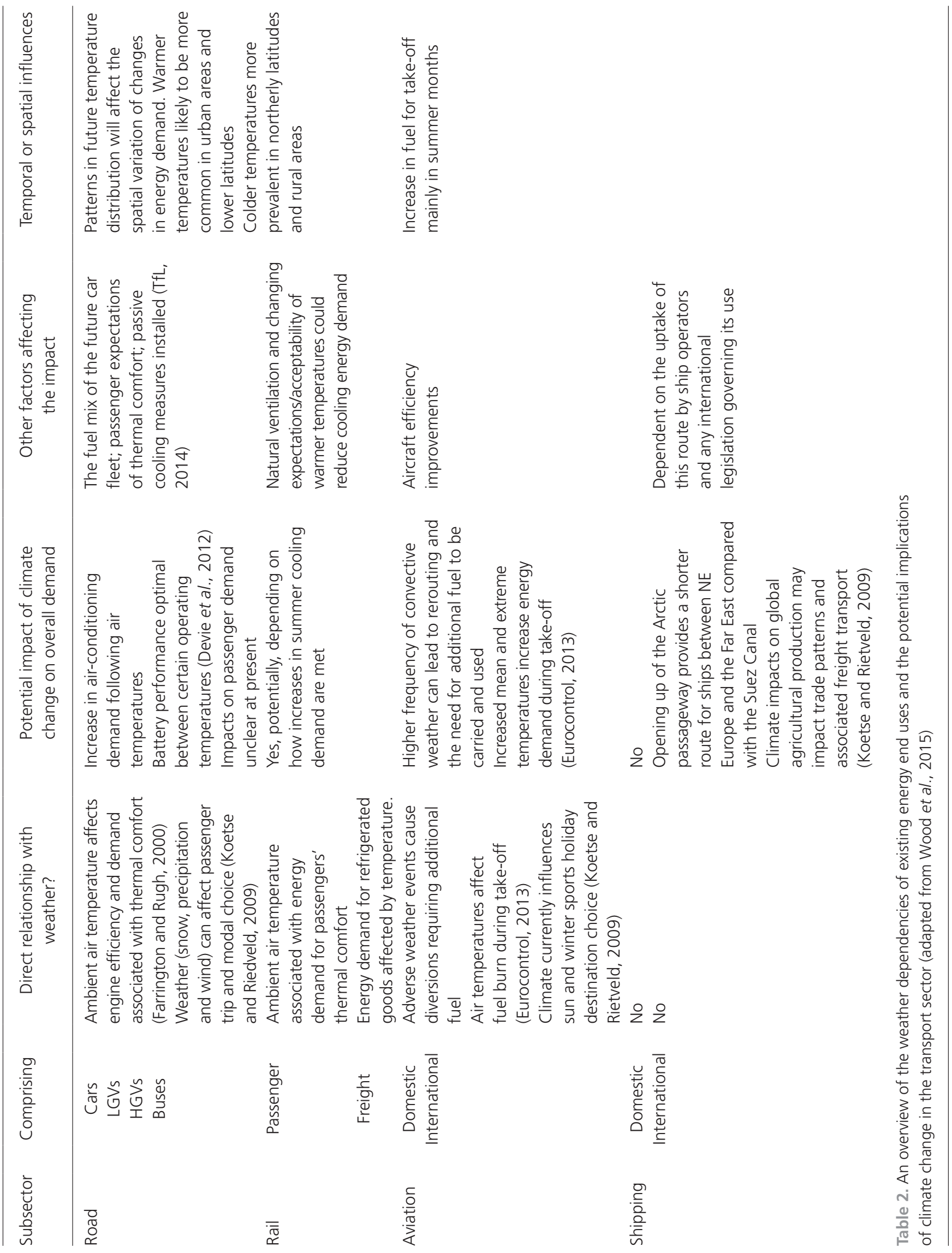


expected to alter EV energy demand markedly in the future with a forecast rise in winter mean temperatures, although extreme cold weather events are likely to remain problematic for users.

Warmer air temperatures are associated with increased use of mobile $\mathrm{AC}$, increasing the electrical load on the battery and more rapidly depleting charge (Devie et al., 2012). The scale of demand change is indeterminate given the elective nature of AC use. However, AC is by far the greatest auxiliary load on a vehicle's battery. Reduction in hybrid and EV 'fuel economy' or range due to AC use is estimated to be up to $40 \%$ - hence a $40 \%$ increase in charging energy to travel the same distance (Farrington and Rugh, 2000). Energy demand for transport AC could potentially increase considerably as mean and peak summer temperatures rise as a result of climate change.

Increasing mean and extreme summer temperatures are also likely to lead to an increase in cooling demand in public modes of transport, although there is insufficient information to determine the significance of this additional load. Increasing demand for cooling on public transport has been observed, however, with London Transport painting bus roofs white and retrofitting automatic ventilation systems to improve passengers' thermal comfort during hot weather (TfL, 2014). Similarly, London Underground has installed pumps, fans and AC units on some lines, incurring energy costs to provide cooling in hot weather (GLA, 2005, 2011). Demand for cooling on the London Underground is likely to increase under all climate scenarios.

For aviation, a potentially significant impact on energy demand arises from an increase in larger and more intense convective systems within the atmosphere. Avoiding these systems typically adds to journey length, requiring additional fuel. An increase in temperature also affects climb performance of aircraft, increasing the fuel demand during takeoff (Eurocontrol, 2013).

\section{Interactions between weather and climate and the energy demand from agriculture}

The UK agriculture industry is, among other factors, shaped by the climate, which determines what is farmed, when and how. Unseasonal weather events are a particular challenge for this sector, such as the prolonged wet period in 2012 that caused extensive flooding and affected both the 2012 harvest and the planting and establishment of the 2013 crops (Defra, 2012). Furthermore, weather also influences the prevalence of agricultural diseases, weeds and pests, thus affecting energy use for agricultural inputs such as pesticides and energy requirements for field operations and pesticide production (Defra, 2012). Although there are a number of studies examining the impacts of climate change on agriculture or adaptation strategies (e.g. Farming Futures, 2011a, 2011b; Hossell and Hughes, 2008), quantification of the impacts on energy demand has not been carried out. Table 3 summarises the existing energy uses in the agricultural industry and considers how these may be affected by climate impacts and the ramifications of emerging trends and adaptation strategies identified on this relationship.

\section{Climate adaptation measures and energy demand}

Much of the climate impacts discussed in the paper to date have considered the impacts of temperature change on existing forms of energy demand. There are a number of additional adaptation or response measures to both incremental changes to 'mean' weather parameters and infrequent but extreme events that require energy services not previously observed at a significant scale in the UK or elsewhere. A number of these are described here, but this is not an exhaustive list - as the climate changes, new innovations may occur to help society respond to these impacts.

Projections of more intense periods of rainfall or sea level rise and higher storm surges require responses if they could lead to flooding. Responses may include flood protection measures, barriers or pumping, which requires energy to operate - potentially in circumstances where supply is also impacted by a flood. Conversely, drier weather in summer is also projected, which, coupled with population growth and industrialisation, increases demands on both surface and groundwater reserves. In these circumstances, without demand response, the energy intensity of water provision and distribution is likely to increase. For example, desalination technologies are one option in response to constraints on water availability. Sea water desalination using reverse osmosis technology can be achieved at a rate of $3 \mathrm{kWh}$ (electricity equivalent)/ $\mathrm{m}^{3}-\mathrm{a}$ figure similar to the energy consumption of freshwater supplies transported over large distances, but significantly higher than the local treatment and supply of freshwater (EPRI, 2000). The difference in energy intensity of desalination compared to traditional water supply is more apparent for alternative techniques such as multistage flash osmosis and multieffect distillation, consuming $13 \cdot 5-25 \cdot 5$ and $6-11 \mathrm{kWh}$ (electricity equivalent) $/ \mathrm{m}^{3}$, respectively. These latter technologies are preferable to reverse osmosis for large-scale industrial use (Desware, 2014).

Many of the geoengineering options under investigation to either mitigate or temporarily protect areas from climate impacts also require energy. The Royal Society's report on geoengineering provides qualitative description on the size of different options, noting several of the methods or stages involved as having significant energy demand or being energy intensive (Royal Society, 2009). This is an area warranting further research.

Furthermore, in addition to the direct energy requirements of adaptation measures, the embodied energy requirements of these technologies can be significant when considering the large range in impacts and technical solutions proposed (Yohanis and Norton, 2002). High-capacity water pumps in addition to direct energy use require energy for their production from raw materials and their transportation. Similarly, other measures include, but are not limited to, the adoption of AC units and fans to cope with hotter temperatures, the use of heat-resistant road-surfacing materials, new drainage systems required to cope with heavy and prolonged rain and sea defences. These measures may all require additional resources and energy compared to those under the current climate. 


\begin{tabular}{|c|c|c|c|c|}
\hline $\begin{array}{l}\text { End use } \\
\text { demand }\end{array}$ & $\begin{array}{l}\text { Direct relationship } \\
\text { with weather? }\end{array}$ & $\begin{array}{l}\text { Potential impact of } \\
\text { climate change on overall } \\
\text { demand }\end{array}$ & $\begin{array}{l}\text { Other factors affecting } \\
\text { the impact }\end{array}$ & $\begin{array}{l}\text { Temporal or spatial } \\
\text { differences }\end{array}$ \\
\hline
\end{tabular}

\begin{tabular}{lllll}
\hline Field & Demand responds to daily & Increased demand for & Alternative farming & Dependent on \\
operations & weather patterns (Hossell & weed control due to & practices could be used & locations of agricultural \\
& and Hughes, 2008) & warmer temperatures & to reduce the size of & productivity and relative \\
& & could increase energy & any increased need for & changes in climate \\
& & required for field & pesticides & between these areas
\end{tabular}

\begin{tabular}{|c|c|}
\hline $\begin{array}{l}\text { Heating and } \\
\text { drying }\end{array}$ & $\begin{array}{l}\text { Colder temperatures } \\
\text { require more energy for } \\
\text { heating. Wetter weather } \\
\text { increases demand for } \\
\text { energy to dry grains } \\
\text { prior to storage (HGCA, } \\
2011 \text { ) }\end{array}$ \\
\hline Ventilation & $\begin{array}{l}\text { Increased ventilation for } \\
\text { livestock and some stored } \\
\text { crops needed during } \\
\text { warmer weather (Farming } \\
\text { Futures, 2011a, 2011b) }\end{array}$ \\
\hline
\end{tabular}

Refrigeration Relates to temperature

Motive power No direct relationship identified

Lighting Some association with cloud cover, but agricultural buildings tend not to rely on natural lighting
Increased cooling demand due to temperature increases

\section{operations. Reduced precipitation requires crop irrigation (Hossell and Hughes, 2008) Annual heating demand likely to reduce. Energy requirements to dry \\ grains likely to increase}

\author{
Impacts could be offset \\ if there is an increase \\ in crops grown in \\ undercover protected \\ areas or in 'indoor farms'
}

Increases in the housing

of livestock either in

response to climate

impacts or as a general

trend would confound

this relationship

Installation of natural

ventilation, mixed mode

cooling provision can

reduce the size of the

impacts of climate

change on energy

demand for cooling

Refrigeration demand

likely to increase in

summer
Demand increases mainly in summer months and after periods of heavy rain

Potential increase during summer months

Table 3. Summary of interactions of weather and climate with demand for energy in the agricultural sector (Wood et al., 2015)

\section{Discussion and conclusions}

The main impact of climate change on energy demand highlighted in the UK CCRA is related to future heat and cooling demand. The literature reviewed and weather and climate dependencies identified here are dominated by the effects of temperature on energy demand. The effects of temperature on energy demand include changing the demand for cooling and refrigeration in buildings, transport, agriculture, storage and industrial processes. In addition, increasing temperatures increase the energy demand for aircraft takeoff (Eurocontrol, 2013). While there have been no significant new studies that quantify the size of the impact on total UK energy demand for comfort cooling or heating since the CCRA was published, a number of studies help understand the influence of location, building fabric and retrofitting options on energy demand in buildings - in particular, 
investigating the trade-offs between insulation measures and heat and cooling demand. However, there is a dearth of literature that attempts to quantify the impacts on temperature or projected temperatures associated with climate change on other sectors. Other impacts of weather and thus future climate change on demand relate to the potential increase in lighting demand during winter daytimes.

Annual energy demand is not the only parameter of importance for system operators. Being able to predict the timing and profile of future energy demand is critical for the planning and smooth operation of supply networks, but more analysis is needed to better understand the ramifications of climate impacts on energy demand according to the time of day as well as the seasons. The literature reviewed here suggests the potential for a marked increase in energy demand for comfort cooling and the maintenance of climatecontrolled environments during summer months, with household demand for comfort cooling potentially causing a new summer evening peak (similar to the current profile of heating demand) and overnight demand during heat waves when temperatures remain high throughout the night. As electricity dominates cooling supply, without strategies to redistribute load, this may compound physical impacts on electricity network ratings of high temperatures and reduce the lifetime of components such as power transmission insulators.

A significant area for further research is to quantify the energy requirements associated with adaptation responses, particularly desalination and geoengineering technologies. The large-scale deployment of geoengineering technologies that deliver net reductions in atmospheric $\mathrm{CO}_{2}$ are relied upon in most future scenarios that deliver $\mathrm{CO}_{2}$ reductions consistent with avoiding more than $2^{\circ} \mathrm{C}$ of global warming (IPCC, 2014). These technologies, alongside other geoengineering options, lead to large point source demand, and their siting will be significant for the transmission network's operation.

The potential ramifications of the above for energy system operators must be considered within the wider system of economic, technological and societal changes that are not directly related to climate change. Some of these changes may strengthen the interdependence between climate and demand (such as the increased use of EVs and ICT), while others may weaken the relationship and have a far greater influence on demand than climate change (such as changes in the structure of the economy). Furthermore, there are some climate impacts that can be moderated, in particular, in ensuring that the building stock is designed or retrofitted to cope with warmer temperatures and reviewing standard set points for internal temperatures to avoid $\mathrm{AC}$ becoming the de facto solution to warmer weather. While there is uncertainty regarding exactly how future demand will evolve in response to sociotechnical change and our responses to climate impacts, one aspect of uncertainty that can be addressed is the level of global warming and the corresponding climate impacts associated with it that could be expected. Although there is still uncertainty regarding the exact impacts associated with increasing global temperatures, as a general rule, the lower the global temperature change, the less severe the impacts. Minimising global temperature change requires collective action to mitigate greenhouse gas emissions and minimise the scale and uncertainty of the impacts to those expected from a low-emission scenario rather than higher, and also requires radical action in the UK and globally and unprecedented levels of annual greenhouse gas reduction (IPCC, 2014).

\section{Practical relevance and potential applications}

The potential type and scale of impacts are relevant to those involved in the long-term planning of energy supply systems. In particular, for electricity network operation, the size of peak load during summer and winter and overnight in summer can influence asset lifespan and, during summer months, when combined with higher temperatures, the capacity. The significance of future hotter temperatures and the effect on the cooling load in buildings is of relevance to the building industry. The building materials, the ability of occupants to manage their environment and the ability to retrofit buildings in the future will have a significant effect on the operational energy demand of buildings. The use of climate projections to assess the thermal performance of building designs can aid the prediction of these impacts.

\section{Acknowledgements}

This work was funded by the LWEC programme of the UK Research Councils and the School of Mechanical, Aerospace and Civil Engineering, University of Manchester.

\section{REFERENCES}

Ackermann M (2002) Cool Comfort: America's Romance with Air Conditioning. Smithsonian Institution Press, Washington, DC.

Auffhammer M and Mansur E (2014) Measuring climatic impacts on energy consumption: a review of the empirical literature. Energy Economics 46: 522-530.

BRE (Building Research Establishment) (2013) Energy Survey Follow Up 2011: Report 9 Domestic Appliances, Cooking and Cooling Equipment (Hulme J, Beaumont A and Summers C (eds)). Prepared by the Building Research Establishment (BRE) on behalf of the Department of Energy and Climate Change, London, UK.

Capon R and Oakley G (2012) UK Climate Change Risk Assessment for the Built Environment. Department of Environment Food and Rural Affairs, London, UK.

Carbon Trust (2012) Air Conditioning: Maximising Comfort, Minimising Energy Demand. Carbon Trust, London, UK.

Chandramowli S and Felder F (2014) Impacts of climate change on electricity systems and markets - a review of models and forecasts. Sustainable Energy Technologies and Assessments 5: $62-74$.

Chappells $\mathrm{H}$ and Shove E (2005) Debating the future of comfort: environmental sustainability, energy consumption and the indoor environment. Building Research and Information 33(1): 32-40.

Chow D and Levermore G (2010) The effects of future climate change on heating and cooling demands in office buildings in the UK. Building Services Engineering Research Technology 31(3): 307-323. 
CIBSE (Chartered Institution of Building Service Engineers) (2006) Degree days: theory and application. The Chartered Institution of Building Service Engineers 2: 6-7.

Collins M, Knutti R, Arblaster J et al. (2013) Long-term climate change: projections, commitments and irreversibility. In Climate Change 2013: The Physical Science Basis. Contribution of Working Group I to the Fifth Assessment Report of the Intergovernmental Panel on Climate Change (Stocker TF, Qin D, Plattner GK et al. (eds)). Cambridge University Press, Cambridge, UK and New York, NY, USA.

Cox (2010) Losing Our Cool. The New Press, New York, USA.

DECC (Department of Energy and Climate Change) (2013a) Energy Consumption in the UK. DECC, London, UK.

DECC (2013b) UK Housing Energy Factfile 2013. Department of Energy and Climate Change, London, UK.

DECC (2014) Digest of UK Energy Statistics. Department of Energy and Climate Change, London, UK.

Defra (Department for Environment, Food and Rural Affairs) (2012) Agriculture in the UK 2012. Department for Environment, Food and Rural Affairs, Department of Agriculture and Rural Development (Northern Ireland), Welsh Assembly Government, The Department for Rural Affairs and Heritage, The Scottish Government, Rural and Environment Research and Analysis Directorate.

Desware (2014) Encyclopaedia of Desalination and Water Resources. Maintained by the Encyclopaedia of Life Support Systems and United Nations Educational Scientific and Cultural Organisation. EoLSS Publishers Co. Ltd, Isle of Man, UK.

Devie A, Vinot E, Pelissier S and Venet P (2012) Real-world battery duty profile of a neighbourhood electric vehicle. Transportation Research Part C: Emerging Technologies 25: 122-133.

Du H, Underwood CP and Edge JS (2012) Generating design reference years from the UKCP09 projections and their application to future air-conditioning loads. Building Services Engineering Research and Technology 33(1): 63-79.

Dunbabin P and Wickins C (2013) Detailed Analysis from the Second Phase of the Energy Saving Trust's Heat Pump Field Trial. Energy Saving Trust and Department for Energy and Climate Change, London, UK.

ENA (Energy Networks Association) (2011) Engineering Report 1 Issue 1: Electricity Networks Climate Change Report. Operations Directorate, Energy Networks Association, London, UK.

EPRI (Electric Power Research Institute) (2000) U.S. Electricity Consumption for Water Supply \& Treatment p1-4 Table 1.1, Electric Power Water \& Sustainability (Volume 4). EPRI, Palo Alto, CA, USA.

Eurocontrol (2013) Challenges of Growth 2013: Task 8 Climate Change Risk and Resilience. European Organisation for the Safety of Air Navigation (EUROCONTROL), Brussels, Belgium.

Farming Futures (2011a) Climate Change Series. Focus on Arable Crops. Fact Sheet 10. Farming Futures, Cambridge, UK.

Farming Futures (2011b) Climate Change Series. Focus on Livestock. Fact Sheet 5. Farming Futures, Cambridge, UK.

Farrington R and Rugh J (2000) Impact of Vehicle AirConditioning on Fuel Economy, Tailpipe Emissions, and Electric Vehicle Range. Earth Technologies Forum, Washington, DC, 31 October.

Gaterell M and McEvoy D (2005) The impact of climate change uncertainties on the performance of energy efficiency measures applied to dwellings. Energy and Buildings 37: 982-995.

GLA (Greater London Authority) (2005) Preparing London's Transport Systems for Climate Change. GLA, London, UK. See http://www.london.gov.uk/media/mayor-pressreleases/2005/09/preparing-londons-transport-systems-for -climate-change (accessed 20/03/14).

GLA (2011) Greater London Authority: Take the Heat Out of Your Journey. See http://www.tfl.gov.uk/corporate/media/ newscentre/metro/20399.aspx (accessed 20/03/2014).

Gupta R and Gregg M (2012) Using UK climate change projections to adapt existing English homes for a warming climate. Building and Environment 55: 20-42.

Hanby S and Smith V (2012) Simulation of the future performance of low-energy evaporative cooling systems using UKCP09 climate projections. Building and Environment 55: 110-115.

HGCA (Home Grown Cereals Authority) (2011) Grain Storage Guide for Cereals and Oilseeds, 3rd edn. Agriculture and Horticulture Development Board, Kenilworth, UK.

Hor C, Watson S and Majitha S (2005) Analyzing the impact of weather variables on monthly electricity demand. IEEE Transactions on Power Systems 20(4): 2078-2085.

Horiba T, Maeshima T, Matsumura T et al. (2005) Applications of high power density lithium ion batteries. Journal of Power Sources 146(1-2): 107-110.

Hossell J and Hughes G (2008) Adapting UK arable agriculture to climate change. $H G C A R \& D$ Conference 'Arable Cropping in a Changing Climate'. 23-24 January.

HPA (Health Protection Agency) (2012) Health Effects of Climate Change in the UK 2012: Current Evidence, Recommendations and Research Gaps (Vardoulakis S and Heaviside C (eds)). HPA, UK. See https://www.gov.uk/government/uploads/ system/uploads/attachment_data/file/371103/Health_Effects of_Climate_Change_in_the_UK_2012_V13_with_cover_ accessible.pdf (accessed 25/07/2015).

IPCC (Intergovernmental Panel on Climate Change) (2014) Climate Change 2014 Synthesis Report Figure SPM.5 (Pachauri R and Meyer L (eds)). Cambridge University Press, Cambridge, UK and New York, NY, USA.

Izham M and Mahlia T (2010) Effect of ambient temperature and relative humidity on $\mathrm{COP}$ of a split room air conditioner. Journal of Energy and Environment 2(1): 35-38.

Jenkins D, Gul M and Patidar S (2013) Probabilistic future cooling loads for mechanically cooled offices. Energy and Buildings 66: $57-65$.

Jentsch M, Bahaj M and James P (2008) Climate change future proofing of buildings - generation and assessment of building simulation weather files. Energy and Buildings 40: 2148-2168.

Kadijk G, Verbeek M, Smokers R et al. (2012) Supporting Analysis Regarding Test Procedure Flexibilities and 
Technology Deployment for Review of the Light Duty Vehicle $\mathrm{CO}_{2}$ Regulations. Final report. European Commission - DG CLIMA, Brussels, Belgium, Project number 033.22993.

Kendrick C, Ogden R, Wang X and Baiche B (2012) Thermal mass in new build UK housing: a comparison of structural systems in a future weather scenario. Energy and Buildings 40: 40-49.

Koetse M and Rietveld P (2009) The impact of climate change on transport a review of empirical findings. Transportation Research Part D 14: 205-221.

Laguerre O, Derens E and Palagos B (2002) Study of domestic refrigerator temperature and analysis of factors affecting temperature: a French survey. International Journal of Refrigeration 25(5): 653-659.

Le Quéré C, Moriarty R, Andrew RM et al. (2014) Global carbon budget 2014. Earth System Science Data Discussions 6: 235-263.

Lomas K and Ji Y (2009) Resilience of naturally ventilated buildings to climate change: advanced natural ventilation and hospital wards. Energy and Buildings 41: 629-653.

Mavrogianni A, Wilkinsdon P, Davies M, Biddulph P and Oikonomou E (2012) Building characteristics as determinants of propensity to high indoor summer temperatures in London dwellings. Building and Environment 55: 117-130.

McColl L, Angelini T and Betts R (2012) UK Climate Change Risk Assessment for the Energy Sector. Department for Environment Food and Rural Affairs, London, UK.

Mock P, German J, Bandivadekar A and Riemersma I (2012) Discrepancies Between Type Approval and "Real-World" Fuel Consumption and $\mathrm{CO}_{2}$ Values: Assessment for 2001-2011 European passenger cars. International Council on Clean Transportation (ICCT). See http://www.theicct.org/fuelconsumption-discrepancies (accessed 25/07/2015).

Murphy J, Sexton D, Jenkins G et al. (2010) UK Climate Projections Science Report: Climate Projections Version 3 Updated December 2010. Met Office Hadley Centre, Exeter, UK.

National Grid (2014a) UK Future Energy Scenarios. National Grid, Warwick, UK.

National Grid (2014b) Electricity Ten Year Statement. National Grid Electricity Transmission, Warwick, UK.

National Grid (2014c) Gas Ten Year Statement 2014. National Grid Gas Plc, Warwick, UK.

Nye D (2010) When the Lights Went Out. The MIT Press, Cambridge, MA, USA.

ONS (Office of National Statistics) (2012). Environmental Accounts: Energy Intensity by Industry (UK Resident Basis). Office of National Statistics, Newport, South Wales. (Data quoted is for 2010 energy consumption).

Patidar S, Jenkins D, Banfill P and Gibson G (2014) Simple statistical model for complex probabilistic climate projections: overheating risk and extreme events. Renewable Energy 61: $23-28$.

Peacock A, Jenkins D and Kane D (2010) Investigating the potential of overheating in UK dwellings as a consequence of extant climate change. Energy Policy 38: 3277-3288.

Perez J (2012) Fundamental principles of transformer thermal loading and protection. 11th IET International Conference on Developments of Power Systems Protection (DPSP 2012), Birmingham, UK. Institution of Engineering and Technology, London, UK.

Royal Society (2009) Geoengineering the Climate: Science, Governance and Uncertainty. Royal Society, London, UK.

Sailor D and Pavlova A (2003) Air conditioning market saturation and long term response of residential cooling energy demand to climate change. Energy 28: 941-951.

Schaeffer R, Szklo A, Pereira de Lucena A et al. (2012) Energy sector vulnerability to climate change: a review. Energy 38: 1-12.

Sexton DMH and Murphy J (2010) UKCP09: Probabilistic Projections of Wind Speed. UK Climate Projections. Met Office Hadley Centre, Exeter, UK. See http://ukclimatepro jections.metoffice.gov.uk $/$ media.jsp?mediaid $=87876 \&$ file type $=$ pdf (accessed 25/07/2015).

Sharples S and Lee S (2009) Climate change and building design. In A Handbook of Sustainable Building Design and Engineering (Mumovic D and Santamouris M (eds)). Earthscan, Oxford, UK, pp. 263-269.

Short C, Lomas K, Giridharan R and Fair A (2012) Building resilience to overheating into 1960's UK hospital buildings within the constraint of the national carbon reduction target: adaptive strategies. Building and Environment 55: 73-95.

Shove E (2003) Comfort, Cleanliness and Convenience: The Social Organisation of Normality. Bloomsbury Academic, London, UK.

Strengers Y (2008) Comfort expectations: the impact of demandmanagement strategies in Australia. Building Research and Information 36(4): 381-391.

TfL (Transport for London) (2014) Transport \& Infrastructure. See http://climatelondon.org.uk/climate-change/climate-changesectors/transport-infrastructure/ (accessed 20/03/2014).

Tian W and de Wilde P (2011) Uncertainty and sensitivity analysis of building performance using probabilistic climate projections: a UK case study. Automation in Construction 20: 1096-1109.

UK Government (2015) Topic Climate Change. See https://www. gov.uk/government/topics/climate-change (accessed 10/04/2015).

Watkins R, Palmer J and Kolokotroni M (2007) Increased temperature and intensification of the Urban Heat Island: implications for human comfort and urban design. Built Environment 33: 85-96.

Wood F, Calverley D, Glynn S et al. (2015) The Impacts of Climate Change on Energy Demand in the UK. LWEC Technical Report. See http://www.lwec.org.uk/.

Yohanis YG and Norton B (2002) Life-cycle operational and embodied energy for a generic single-story office building in the UK. Energy 27: 77-92.

\section{WHAT DO YOU THINK?}

To discuss this paper, please submit up to 500 words to the editor at journals@ice.org.uk. Your contribution will be forwarded to the author(s) for a reply and, if considered appropriate by the editorial panel, will be published as a discussion in a future issue of the journal. 